\title{
Statistical optimization for improved indole-3-acetic acid (iaa) production by Pseudomonas aeruginosa and demonstration of enhanced plant growth promotion
}

\author{
B. Sasirekha ${ }^{1}$, S. Shivakumar ${ }^{1 *}$, S.B. Sullia ${ }^{1}$

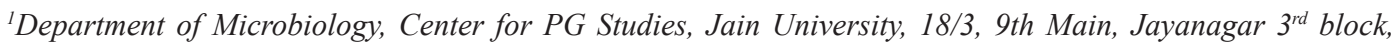 \\ Bangalore-560011, India. *Corresponding author: sk2410@yahoo.co.uk
}

\begin{abstract}
The present study was undertaken to study the statistical optimization of medium components for improved Indole-3- acetic acid (IAA) production by Pseudomonas aeruginosa. Colorimetric analysis showed maximum IAA $\left(132 \mu \mathrm{g} \mathrm{mL}^{-1}\right)$ in the medium supplemented with tryptophan $\left(0.5 \mathrm{~g} \mathrm{~L}^{-1}\right)$. The maximum production was achieved after $96 \mathrm{~h}$ of incubation. Yeast extract, tryptophan and EDTA were identified as significant components influencing IAA production by Pseudomonas aeruginosa, using the Plackett- Burman method. The statistical optimization approach led to the production of $318 \mu \mathrm{g} \mathrm{mL}^{-1}$ of IAA within $24 \mathrm{~h}$ of incubation. Statistical approach was found to be very effective in optimizing the medium components in a manageable number of experimental runs with overall 2.4 fold increase in IAA production. TLC and GC-MS analysis further confirmed the IAA production in the cell filtrates of the strain. GC-MS analysis and tryptophan side chain oxidase confirmed the existence of atleast 2 possible pathways for IAA by this strain. Inoculation of $P$. aeruginosa culture filtrate enhanced seed germination (82.4\%) and increase in root length and shoot length $(\sim 2.6$ and $\sim 1.1$ folds over the control) of cowpea seeds over the control treatment under pot culture conditions.
\end{abstract}

Keywords: indole-3- acetic acid, Plackett- Burman Design, Pseudomonas aeruginosa, GC-MS, seed bacterization. 


\section{Introduction}

Indole-3-acetic acid (IAA) is the main member of the auxin family that controls many important physiological processes including cell enlargement and division, tissue differentiation, and responses to light and gravity (Teale et al., 2006). Various microorganisms including bacteria, fungi, and algae are capable of producing physiologically active quantities of auxins, which may exert pronounced effects on plant growth and establishment. Bacteria inhabiting rhizosphere of various plants are known as "plant growth promoting rhizobacteria (PGPR)". These bacteria synthesize and release greater amount of IAA as secondary metabolite because of the substrates exuded from the roots, when compared with nonrhizospheric soil bacteria and promote plant growth directly (Spaepen et al., 2007). The IAA produced by bacteria colonizing the rhizosphere of the plants is proposed to act in conjunction with endogenous IAA in plant to stimulate cell proliferation, elongation, and enhancement of host's uptake of minerals and nutrients from the soil (Suzuki and Oyaizu, 2003; Leveau and Lindow, 2005). IAA also serves as a regulating agent for microbial cell differentiation, for example, it stimulates spore germination and mycelial elongation in a Streptomyces, and induces adhesion and filamentation in Saccharomyces cerevisiae (Matsukawa et al., 2007). These results suggest that IAA may act on a common regulatory cascade leading to morphogenesis and secondary metabolism (Diemaite, 2004).

Tryptophan is believed to be the primary precursor for the formation of IAA in plants and microorganisms (Monteiro et al., 1988). Different bacterial pathways to synthesize IAA have been identified and a high degree of similarity between IAA biosynthe- sis pathways in plants and bacteria was observed (Spaepen et al., 2007).

Traditional experimental design often uses "one factor at a time" with only one factor of a system being variable, while the other factors are kept fixed during each trial and therefore, in this method a number of experiments are required. Statistical methods have advantages over conventional methodologies in predicting the accurate results basically due to utilization of fundamental principles of statistics, randomization, and replication. In full factorial designs, the number of factors increases exponentially leading to an unmanageable number of experiments. Hence, fractional factorial design like Plackett- Burman becomes a method of choice for initial screening of medium components. Plackett- Burman's statistical method involves a two-level fractional factorial saturated design that uses only $k+1$ treatment combinations to estimate the main effects of $\mathrm{k}$ factors independently (assuming that all interactions are negligible) (Plackett and Burman 1946).

The species of genus Pseudomonas are widely distributed in nature and act as plant growth-promoting rhizobacteria by nitrogen fixation, mineral solubilization, as well as transformation of nutrients, production of phytohormones and siderophores, and 1-aminocyclopropane-1-carboxylic acid (ACC) deaminase (Lugtenberg and Kamilova, 2009). Although IAA production has been reported in Pseudomonas species (Karnwal, 2009), there is not much information on statistical optimization of nutritive conditions for its production. Hence, the present report is an attempt to optimize medium components for improved IAA production by the potential biocontrol agent Pseudomonas aeruginosa. 


\section{Materials and methods}

\subsection{Organism and culture conditions}

The IAA producing bacterium was isolated from the rhizospheric soil of various vegetable crops from in and around Bangalore, India. The potential isolate was identified as Pseudomonas aeruginosa through morphological and biochemical characteristics and by $16 \mathrm{~S}$ rDNA sequence analysis. The nucleotide sequence of the 16S rRNA of Pseudomonas aerugonisa FP6 has been deposited in the GenBank database under the accession number JN861778.

\subsection{Quantitative estimation of IAA production}

IAA production was determined using Salkowaski reagent as described by Gordon and Weber (1951). $100 \mu \mathrm{L}$ of $24 \mathrm{~h}$ bacterial broth $\left(10^{8} \mathrm{cfu} \mathrm{mL}^{-1}\right)$ was inoculated into $100 \mathrm{~mL}$ of nutrient broth medium in $250 \mathrm{~mL}$ flask containing $0.1 \mathrm{mg} \mathrm{mL}^{-1} \mathrm{~L}$-tryptophan. The flask was incubated at $30^{\circ} \mathrm{C}$ temperature for $48 \mathrm{~h}$ in a rotary shaker $(120$ $\mathrm{rpm})$. Then, the culture was centrifuged for $30 \mathrm{~min}$ at $10,000 \mathrm{rpm}$. Two $\mathrm{mL}$ of the supernatant was mixed with equal volume of Salkowski reagent $\left(0.5 \mathrm{M} \mathrm{FeCl}_{3}\right.$ in 35 $\%$ perchloric acid). The contents were mixed by shaking and allowed to stand at room temperature for $30 \mathrm{~min}$ till the development of pink color. Quantitative estimation of IAA was made by spectroscopic absorbance measurements at a wavelength of $535 \mathrm{~nm}$. Uninoculated broth served as control. IAA concentration values were obtained by preparing a standard curve from IAA solution $\left(0-100 \mu \mathrm{g} \mathrm{mL}^{-1}\right)$ and the amount of IAA produced was expressed as $\mu \mathrm{g}$ IAA secreted per unit of optical density.

\subsection{Effect of tryptophan concentration on IAA production}

Erlenmeyer flasks containing $50 \mathrm{~mL}$ of nutrient broth were supplemented with different concentrations of L- tryptophan (0- $\left.1 \mathrm{~g} \mathrm{~L}^{-1}\right)$ and inoculated with $100 \mu \mathrm{L}$ of the bacterial cell suspension $\left(10^{8} \mathrm{cfu} \mathrm{mL}^{-1}\right)$. After incubation, growth was measured at $\mathrm{OD}_{600 \mathrm{~nm}}$ and culture supernatants were collected and assayed for IAA production as described above.

The unoptimized medium used for growth and IAA production consisted of the following $\left(\mathrm{g} \mathrm{L}^{-1}\right)$ : peptone, 5 ; yeast extract, 3 ; $\mathrm{NaCl}, 5$; tryptophan, $0.1 ; \mathrm{pH} 7.2$ at $30^{\circ} \mathrm{C}$ under shaking conditions (120 rpm) for 96 hours . The media components and their composition for IAA production during optimization study are given in Tables 1 and 2.

Table 1. Variables representing medium components used in Plackett- Burman design.

\begin{tabular}{cccc}
\hline Variables & Medium components (factors) & Low level (-) & High level (-) \\
\hline $\mathrm{X}_{1}$ & Glucose $\left(\mathrm{g} \mathrm{L}^{-1}\right)$ & 0.1 & 1 \\
$\mathrm{X}_{2}$ & Glycerol $\left(\mathrm{g} \mathrm{L}^{-1}\right)$ & 0.1 & 0.1 \\
$\mathrm{X}_{3}$ & $\mathrm{KNO}_{3}\left(\mathrm{~g} \mathrm{~L}^{-1}\right)$ & 0.02 & 0.2 \\
$\mathrm{X}_{4}$ & Yeast extract $\left(\mathrm{g} \mathrm{L}^{-1}\right)$ & 0.05 & 0.5 \\
$\mathrm{X}_{5}$ & Tryptophan $\left(\mathrm{g} \mathrm{L}^{-1}\right)$ & 0.1 & 1 \\
$\mathrm{X}_{6}$ & $\mathrm{pH}$ & 5 & 7.5 \\
$\mathrm{X}_{7}$ & Temperature $\left({ }^{\circ} \mathrm{C}\right)$ & 20 & 37 \\
$\mathrm{X}_{8}$ & Incubation time $(\mathrm{h})$ & 24 & 96 \\
$\mathrm{X}_{9}$ & $\mathrm{NaCl}\left(\mathrm{g} \mathrm{L}^{-1}\right)$ & 0.01 & 0.1 \\
$\mathrm{X}_{10}$ & EDTA $\left(\mathrm{mg} \mathrm{mL}^{-1}\right)$ & 0.0002 & 0.02 \\
$\mathrm{X}_{11}$ & Aeration $\left(\mathrm{rev} \mathrm{min}^{-1}\right)$ & static & 120 \\
\hline
\end{tabular}




\subsection{Evaluation of environmental factors for IAA production using Plackett- Burman experimental design}

Identification of essential medium constituents to improve IAA production by Pseudomonas aerugonisa was carried out using Plackett- Burman statistical design (Plackett and Burmann, 1946). A total of eleven variables (variable $k=11$, table1) were selected for the study with each variable representing two level, high (+) and low (-) in 12 trials (Table 2). The number of positive and negative signs per trial was $(k+1) / 2$ and $(k-2) / 2$, respectively. Each row represents a trial, and each column represents an independent (assigned) variable. The effect of each variable was determined by the following equation:

$$
\mathrm{E}\left(X_{\mathrm{i}}\right)=2\left(\sum \mathrm{M}_{\mathrm{i}}^{+}-\mathrm{M}_{\mathrm{i}}^{-}\right) / N
$$

Where, $\mathrm{E}\left(X_{\mathrm{i}}\right)$ is the concentration effect of the tested variables. $\mathrm{M}_{\mathrm{i}}^{+}$and $\mathrm{M}_{\mathrm{i}}^{-}$represent IAA production from the trials, where the independent variable $\left(X_{\mathrm{i}}\right)$ measured was present at high and low concentrations, respectively. $N$, total number of the trials equals to 12 . When the sign is positive, the influence of the variable upon IAA production is greater at higher concentration, and when negative, the influence of the variable is greater at low concentration. The standard error (SE) of concentration effect was the square root of the variance of an effect, and the significance level $(P$ value) of each concentration effect was determined using the Student's $t$ - test:

$$
t\left(X_{\mathrm{i}}\right)=\mathrm{E}\left(X_{\mathrm{i}}\right) / \mathrm{SE}
$$

Where, $\mathrm{E}\left(X_{\mathrm{i}}\right)$ is the effect of variable $\mathrm{X}_{\mathrm{i}}$. The statistical analysis of the results was performed with the aid of statistical software package design expert 8.0 (State-Ease, Minneapolis, MN, USA).

\subsection{Extraction of Crude IAA}

IAA was produced in optimized culture conditions. Bacterial cells were separated from the supernatant by centrifugation at $10,000 \mathrm{rpm}$ for $30 \mathrm{~min}$. The supernatant was acidified to $\mathrm{pH} 2.5-3.0$ with $1 \mathrm{~N} \mathrm{HCl}$ and extracted twice with ethyl acetate at double the volume of the supernatant. An extracted ethyl acetate fraction was evaporated dry in a rotary evaporator at $40^{\circ} \mathrm{C}$. The extract was dissolved in $1 \mathrm{~mL}$ of methanol and kept at $-20^{\circ} \mathrm{C}$.

\subsection{Thin Layer Chromatography}

Ethyl acetate fractions $(10-20 \mu \mathrm{L})$ were plated on TLC plates (Silica gel G f254, thickness $0.25 \mathrm{~mm}$ ) and developed either in ethyl acetate: chloroform: formic acid (55:35:10,v/v) or benzene: n-butanol: acetic acid $(70: 25: 5, \mathrm{v} / \mathrm{v})$. Spots with $\mathrm{R}_{f}$ values identical to authentic IAA, were identified both under UV light $(254 \mathrm{~nm})$ and by spraying Salkowski reagent, and compared with $\mathrm{R}_{f}$ of pure IAA as positive control.

\section{7. $G C-M S$}

The methylated compound and standard IAA were subjected to gas chromatography- mass spectrometry (Thermo FinniganLCQ Deca XP MAX mass spectrometer, thermo Electron Corporation). GC- MS was quipped with a TR-5 capillary column (30 m length, $0.25 \mu \mathrm{m}$ thickness, $0.25 \mathrm{~mm}$ diameter). The helium flow rate was $1.2 \mathrm{~mL} \mathrm{~min}^{-1}$ and the injector temperature was $250^{\circ} \mathrm{C}$. A temperature program of $120-220^{\circ} \mathrm{C}$ at $3^{\circ} \mathrm{C} \mathrm{min}^{-1}$ was started upon injection. Mass spectra were recorded at an ionizing voltage of $70 \mathrm{eV}$ with a source temperature of $270^{\circ} \mathrm{C}$. The identity of extracted compound, as IAA was determined on the basis of its retention time as compared to the data of GC- MS analysis of methylated standard IAA. 


\subsection{Detection of tryptophan side chain oxidase}

Plate test for tryptophan side chain oxidase (TSO), as a pathway in IAA biosynthesis was performed by a modified method of Takai and Hayaishi (1987). P. aeruginosa was streaked over King's B medium and overlaid with $6.0 \mathrm{ml}$ of soft agar containing $10 \%(\mathrm{w} / \mathrm{v})$ SDS and $20 \mathrm{mM}$ L- tryptophan in $1 \mathrm{M}$ glycine- HCL buffer (pH- 3). Plates were kept at room temperature for 4 hrs. Change in the color of streaked cells was observed as a score for TSO production.

\subsection{The effects of crude IAA extract of $P$. aeruginosa on seed germination and root elongation of cowpea}

The seeds of cowpea, Vigna unguiculata C-152, were used throughout the study. Cowpea seeds used for the experiments were obtained from University of Agricultural Sciences, GKVK, Bangalore. The cowpea seeds were surface sterilized in $70 \%$ ethanol for $2 \mathrm{~min}$ and in $2 \%$ sodium hypochlorite for $5 \mathrm{~min}$ and then washed ten times in sterile distilled water. P. aerugonisa was grown in nutrient broth supplemented with $0.5 \%$ L-tryptophan, $\mathrm{pH} 7.0$ and incubated at $30^{\circ} \mathrm{C}$ for 5 days. Bacterial cells were separated from the supernatant by centrifugation at $11,000 \mathrm{rpm}$ for $15 \mathrm{~min}$. The supernatant was filtered (Millipore filter, $0.45 \mu \mathrm{m}$ ) and the cell-free filtrate was used for subsequent test. The surface sterilized seeds were then soaked in culture filtrate containing sterilized carboxymethylcellulose $(\mathrm{CMC} ; 1 \%)$ as an adhesive in a shaker incubator at $120 \mathrm{rpm}$ for $6 \mathrm{hrs}$, then air-dried. Seeds treated with sterile distilled water amended with $\mathrm{CMC}$ alone served as control. Seeds were sown in plastic pots containing sterile sand. Seed germination, seedling vigor and the measurements of root length of cowpea were analyzed 10 days after germination. The experiment was carried out with three replicates of 50 seeds each.

\subsection{Statistical analysis}

Data regarding the effect of culture-filtrate on seed germination and root elongation of cowpea was statistically analyzed by Student's $t$ - test (SPSS software 18).

\section{Results and discussion}

Pseudomonads are predominantly found in rhizosphere of cereal and legume crops. These rhizobacteria have immense potential in agriculture for use as biofertilizer, biocontrol agent and in bioremediation due to their plant growth-promoting ability, antimicrobial activity and ability to degrade pollutants (Ahmad et al., 2008). Production of plant growth hormones, particularly IAA, has long been considered an important attribute of PGPR strains and different bacterial strains were found to produce IAA.

\subsection{Effect of tryptophan concentration on IAA production}

The isolate produced $80 \mu \mathrm{g} \mathrm{mL}^{-1}$ (5 fold) increase in IAA production on tryptophan supplementation $(0.1 \mathrm{~g}$ $\mathrm{L}^{-1}$ ) when compared to control (without tryptophan). IAA production started after $24 \mathrm{~h}$ of incubation and reached a maximum at 96 hours followed by a decrease. $P$. aeruginosa produced higher IAA in the presence of the precursor, L-tryptophan which shows that the isolate is dependent on the L-tryptophan precursor and probably synthesized IAA through L-tryptophan dependent pathways. El- Khawas and Adachi (1999) showed that K. pneumoniae and Azospirillum brasilense produced 35 and $46 \mu \mathrm{g} \mathrm{mL}^{-1}$ of IAA with tryptophan supplementation. Similarly, $38 \mu \mathrm{g} \mathrm{mL}^{-1}$ and $80 \mu \mathrm{g} \mathrm{mL}^{-1}$ of IAA production were reported in Serratia plymuthica and Paenibacillus polymyxa (Phi et al., 2008; Koo et al., 2009). Our strain produced comparably higher amount 
of the IAA than some of the other analyzed strains in literature which shows that different isolates vary in their utilization of different concentrations of L-tryptophan for IAA production.

The isolate also exhibited tryptophan concentration dependent IAA production. The IAA production increased from $80 \mu \mathrm{g} \mathrm{mL}^{-1}$ to $132 \mu \mathrm{g} \mathrm{mL}^{-1}$ with increasing concentration of tryptophan from $0.1 \mathrm{~g} \mathrm{~L}^{-1}$ to $0.5 \mathrm{~g}$ $\mathrm{L}^{-1}$ after which there was a slight decrease. This may be due to release of IAA degrading enzymes as reported earlier in Rhizobium species (Datta and Basu, 2000).

\subsection{Optimization of culture conditions by Plackett- Burman experimental design}

Statistical methods for medium optimization have proved to be a powerful and useful tool for biotechnology. The data in Table 2 indicated that there was a wide variation for IAA production in 12 runs. This variation reflects the importance of medium optimization to attain higher yields.
The main effect of each variable upon IAA production was estimated. Within the range of the tested variables, the factors that appeared to be of positive effects are glucose, glycerol, yeast extract, tryptophan, salt, EDTA, aeration. Figure 1 (pareto chart) shows, the positive and negative influence of the screened variables on IAA production. On the other hand, high levels of the other variables showed negative effects on IAA production. Statistical analyses of data showed that yeast extract, tryptophan, EDTA in the tested range of variables had the most significant effects on IAA production. Yeast extract is the most significant factor with positive effect for IAA production and this factor gave the maximum sum of squares and percentage influence $(31.91 \%)$, whereas carbon source (glucose and glycerol) has only 5.67 and $6.56 \%$ contribution within the tested levels, aeration, incubation period and $\mathrm{pH}(0.477,0.28$ and 0.02$)$ were the least contributing factors (Table 3 ).

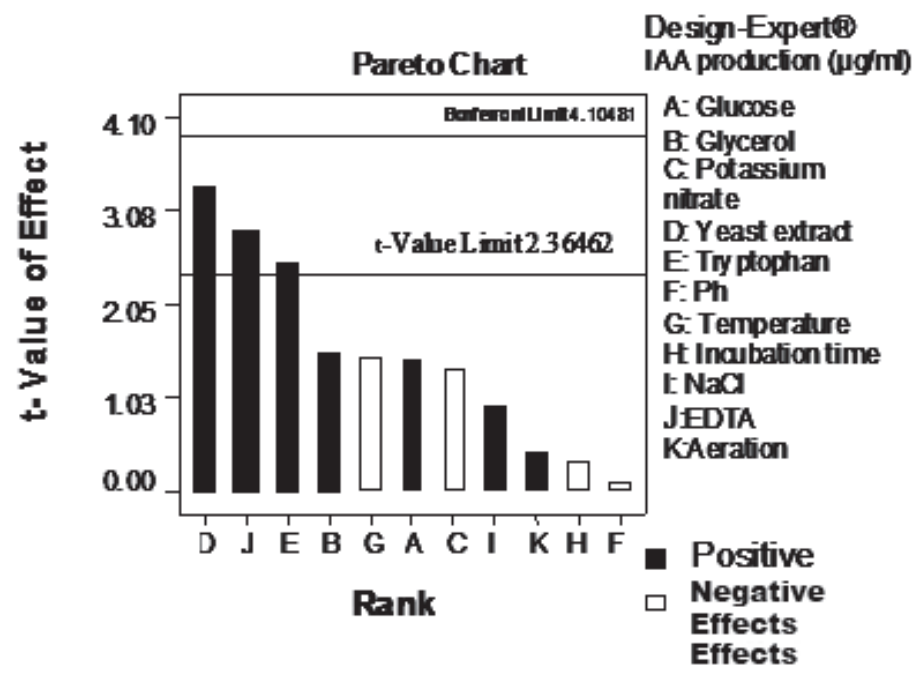

Figure 1. Pareto chart of eleven factors standard effects on IAA production. 
Table 2. Plackett- Burman experimental design matrix with the observed response (IAA production).

\begin{tabular}{ccccccccccccc}
\hline & \multicolumn{10}{c}{ Variables } & \multicolumn{1}{c}{ IAA production $\left(\mu \mathbf{g ~ m L}^{-1}\right)$} \\
\cline { 2 - 9 } & $\mathbf{X}_{1}$ & $\mathbf{X}_{2}$ & $\mathbf{X}_{3}$ & $\mathbf{X}_{4}$ & $\mathbf{X}_{5}$ & $\mathbf{X}_{6}$ & $\mathbf{X}_{7}$ & $\mathbf{X}_{8}$ & $\mathbf{X}_{9}$ & $\mathbf{X}_{10}$ & $\mathbf{X}_{11}$ & 66 \\
2 & - & - & - & - & - & - & - & - & - & - & - & 166 \\
3 & - & - & + & - & + & + & - & + & + & + & - & 225 \\
4 & + & - & + & + & + & - & - & - & + & - & + & 184 \\
5 & - & + & + & - & + & + & + & - & - & - & + & 100 \\
6 & - & + & + & + & - & - & - & + & - & + & + & 208 \\
7 & + & + & - & - & - & + & - & + & + & - & + & 150 \\
8 & + & - & + & + & - & + & + & + & - & - & - & 100 \\
9 & + & + & - & + & + & + & - & - & - & + & - & 318 \\
10 & + & + & + & - & - & - & + & - & + & + & - & 152 \\
11 & - & - & - & + & - & + & + & - & + & + & + & 196.5 \\
12 & - & + & - & + & + & - & + & + & + & - & - & 208 \\
\hline
\end{tabular}

$\mathrm{X}_{1}-\mathrm{X}_{7}$ represent different assigned variables; the values are placed at different levels of variables, sign ' + ' is for high concentration of variables and '-' is for low concentration of variables.

Table 3. Degree of positive or negative effect independent variables on IAA production by P. aerugonisa according to levels in the Placket- Burman experimental design.

\begin{tabular}{ccccccc}
\hline Variables & Medium components & Effect & $\mathbf{S E}$ & $\mathbf{t}\left(\mathbf{X}_{\mathbf{i}}\right)$ & $\mathbf{p}$-value & Significance level \\
\hline $\mathrm{X}_{1}$ & Glucose & 30.75 & 10.91 & 2.81 & 0.10 & $\mathrm{~N} . \mathrm{S}$ \\
$\mathrm{X}_{2}$ & Glycerol & 33.08 & 10.91 & 3.03 & 0.09 & $\mathrm{~N} . \mathrm{S}$ \\
$\mathrm{X}_{3}$ & $\mathrm{KNO}_{3}$ & -28.53 & 10.91 & -2.61 & 0.12 & $\mathrm{~N} . \mathrm{S}$ \\
$\mathrm{X}_{4}$ & Yeast extract & 72.91 & 10.91 & 6.68 & 0.02 & $\mathrm{~S}$ \\
$\mathrm{X}_{5}$ & Tryptophan & 54.75 & 10.91 & 5.01 & 0.03 & $\mathrm{~S}$ \\
$\mathrm{X}_{6}$ & pH & -2.08 & 10.91 & -0.19 & 0.86 & $\mathrm{~N} . \mathrm{S}$ \\
$\mathrm{X}_{7}$ & Temperature & -32.08 & 10.91 & -2.94 & 0.09 & $\mathrm{~N} . \mathrm{S}$ \\
$\mathrm{X}_{8}$ & Incubation time & -6.91 & 10.91 & 0.63 & 0.59 & $\mathrm{~N} . \mathrm{S}$ \\
$\mathrm{X}_{9}$ & Nacl & 20.25 & 10.91 & 1.85 & 0.20 & $\mathrm{~N} . \mathrm{S}$ \\
$\mathrm{X}_{10}$ & EDTA & 62.58 & 10.91 & 5.73 & 0.02 & $\mathrm{~S}$ \\
$\mathrm{X}_{11}$ & Aeration & 8.91 & 10.91 & 0.81 & 0.50 & N.S \\
\hline
\end{tabular}

$X_{1}-X_{7}$ represents different assigned variables; $\mathrm{SE}$ is the standard error; $t\left(X_{\mathrm{i}}\right)$ is the value of the variables determined by student's $t$ - test, and $i=1-11$. 
Figure 3 shows the actual values for IAA produced and the predicted values determined by the model. The higher values of R-squared (0.799) and adjusted R-squared (0.6855) indicated the efficacy of the model. Adequate precision ratio of 9.153 indicates an adequate signal. The statistical analysis indicates that the proposed model was adequate with very satisfac- tory values of the R-Squared. The adjusted $\mathrm{R}^{2}$ is adjusted for the number of terms in the model. It decreases as the number of terms in the model increases, if those additional terms do not add value to the model. Adequate precision is a signal-to-noise ratio. It compares the range of the predicted values at the design points to the average prediction error.

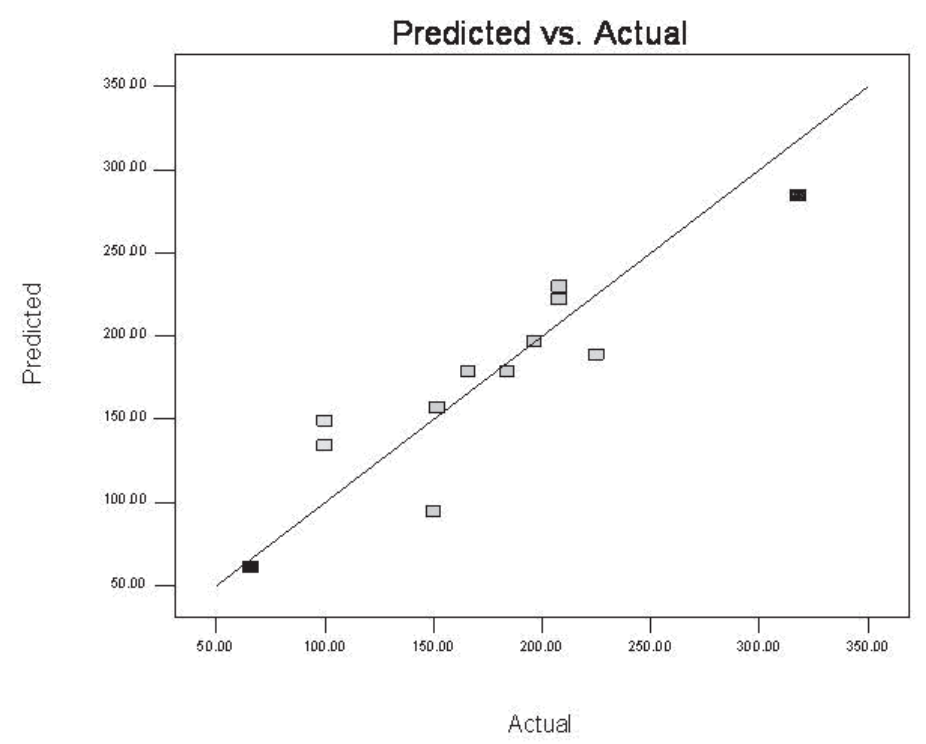

Figure 2. Plot of predicted $v s$ actual IAA activity ( $\mu \mathrm{g} \mathrm{mL} \mathrm{m}^{-1}$ values) of $P$. aerugonisa.

According to the data obtained from the PlackettBurman experimental results, the medium predicted to be near optimum should be of the following composition $\left(\mathrm{g} \mathrm{mL}^{-1}\right)$ : glucose, 0.01 ; yeast extract, 0.01; tryptophan, 0.005; $\mathrm{NaCl}, 0.02$; EDTA $0.5 ; \mathrm{pH}$ 7 incubation at shaking condition for $24 \mathrm{hrs}$. On optimization the production of IAA increased to $318 \mu \mathrm{g}$ $\mathrm{mL}^{-1}$ within $24 \mathrm{hrs}$, which was 2.4 times higher than in the unoptimized medium.

\section{3. $T L C$ and $G C-M S$}

The production of IAA was confirmed by TLC and by GC- MS analysis. Chromatogram of culture extract spot and standard IAA when observed under UV light showed the same $\mathrm{R}_{\mathrm{f}}$ value 0.88 . The TLC findings are in agreement with other reports (Kang et al., 2006). By GC-MS analysis, the extracted methylated compounded was further confirmed as IAA. The retention 
time (8.68 $\mathrm{min}$ ) of methylated compound was comparable to the reference standard (methyl esters of standard IAA) (Figure 3a,b). The GC-MS analyses of the culture supernatants and standard showed the electron impact mass spectra of indole-3-acetamide peak which indicates that IAA is produced via Indole-3-acetamide pathway. This pathway appears to be prevalent in bacteria (Persello Cartieaux et al., 2003).
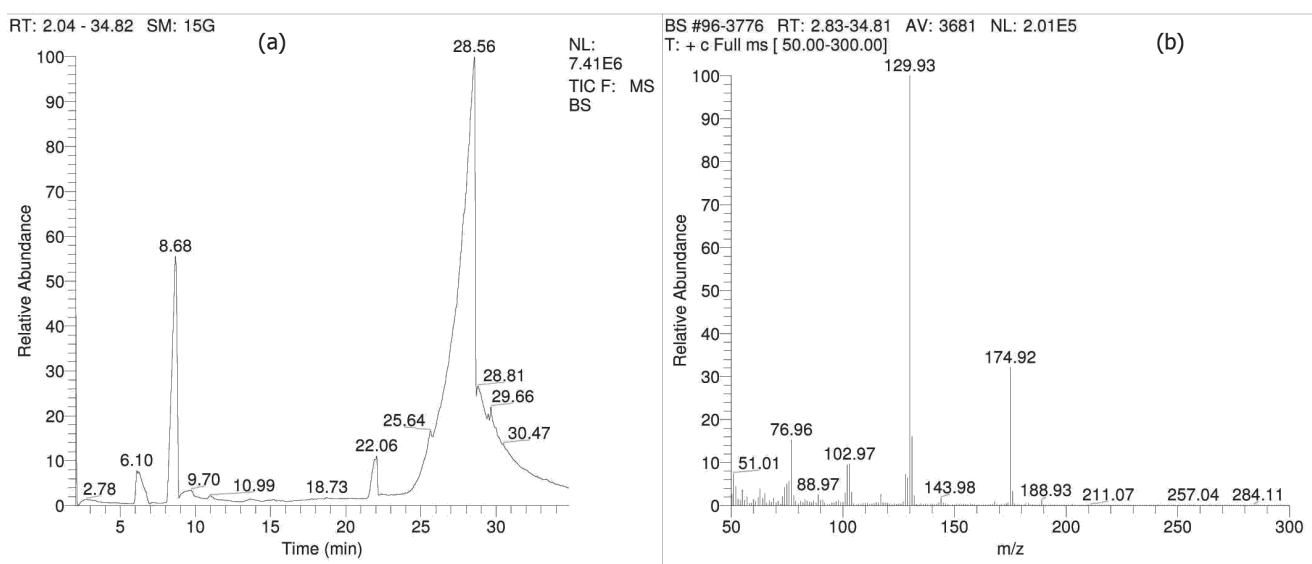

Figure 3. Electron impact $(70 \mathrm{eV})$ mass spectra of (a). Retention time of methylated sample of IAA. MethylIAA is at $\mathrm{R} f=8.68 \mathrm{~min}$. (b) Methylated sample of putative IAA isolated from Pseudomonas aeruginosa. Ions characteristics of methyl IAA are $m / z$ 174.92( $M+$ ), 129.82 (base peak) and 102.89.

\subsection{Tryptophan side chain oxidase}

In order to delineate the possibility of another pathway of IAA synthesis, tryptophan side chain oxidase (TSO) as a pathway enzyme was detected qualitatively on agar plate. The over laid soft agar cocktail containing bacteria changed in color from straw to dark brown. In the present study, TSO was detected as an additional pathway for IAA production

\subsection{Effect of P. aeruginosa on Plant growth}

The property of synthesizing indole acetic acid is considered as an effective tool for screening beneficial microorganisms as there have been reports suggesting that IAA producing bacteria have a profound effect on plant growth (Ali and Hasnain,
2007). Thus, $P$. aeruginosa was further studied for its effect on plant growth under controlled conditions. The seed germination index was higher in bacterized seeds $(82.4 \%)$, which germinated earlier in comparison to the control $(69.3 \%)$. Treated cowpea seedlings were different from the untreated in morphological parameters like plant height and root length. The inoculation of cowpea seeds with isolate $P$. aeruginosa has significant $(p>0.01)$ effect on roots as compared with the control. The isolate had most favorable effect over root length and shoot length $(\sim 2.6$ and $\sim 1.1$ folds over the control), fresh root weight ( $\sim 2.4$ folds over the control), as well as root dry weight ( $\sim 2.6$ folds over the control). The results indicated that our strain $P$. aeruginosa can improve the root development and thus can be considered as plant growth promoters. 
Table 4. Effect of inoculation of the Pseudomonas aeruginosa on cowpea (Vigna unguiculata).

\begin{tabular}{lcc}
\hline \multicolumn{1}{c}{ Attributes } & control & P. aeruginosa \\
\hline Seed germination (\%) & 73.33 & 100 \\
Vigour index & 322.96 & 614.04 \\
Shoot length $(\mathrm{cm})$ & $6.11 \pm 2.5$ & $6.73 \pm 2.2$ \\
Root length $(\mathrm{cm})$ & $3.72 \pm 1.8$ & $8.35 \pm 3.9^{*}$ \\
Fresh shoot weight $(\mathrm{g})$ & $0.31 \pm 0.1$ & $0.29 \pm 0.09$ \\
Fresh root weight $(\mathrm{g})$ & $0.05 \pm 0.07$ & $0.12 \pm 0.03^{*}$ \\
Dry shoot weight $(\mathrm{g})$ & $0.04 \pm 0.19$ & $0.05 \pm 0.016$ \\
Dry root weight $(\mathrm{g})$ & $0.005 \pm 0.004$ & $0.013 \pm 0.01^{*}$ \\
\hline
\end{tabular}

Results obtained were of mean of triplicates $\pm \mathrm{sd}$. Data was analyzed using students $t$-test. ${ }^{*}$ Highly significant

\section{Conclusions}

The statistical optimization method is widely used and has a growing acceptance. Till date, there is no information on statistical optimization of medium components for IAA production by Pseudomonas aerugonisa by a statistical design. The present study provides a suitable medium for improved IAA production by Pseudomonas aerugonisa. Further, the finding of the present study highlighted that IAA-producing bacteria from rhizospheric soil can be easily isolated and may be exploited for local agricultural use. The isolate has a potential to be used as plant biofertilizer or bioenhancer for plant growth improvement.

\section{References}

Ahmad, F., Ahmad, I., Khan, M.S. 2008. Screening of freeliving rhizosphere bacteria for their multiple plant growth promoting activities. Microbiol. Res. 163, 173- 181.

Ali, B., Hasnain, S. 2007. Potential of bacterial indoleacetic acid to induce adventitious shoots in plant tissue culture. Lett. Appl. Microbiol. 45,2,128- 133 .
Datta, C., Basu, P.S. 2000. Indole acetic acid production by Rhizobium species from root nodules of a leguminous shrub, Cajanus cajan. Microbiol. Res. 155, 123- 127.

Diemaite, J. 2004. Peculiarities of the formation of indole-3- acetic acid- protein complexes in yeast Saccharomyces cerevisiae plasmalemma. Biologia. 10, 36- 38.

El-Khawas, H., Adachi, K. 1999. Identification and quantification of auxins in culture media of Azospirillum and Klebsiella and their effect on rice roots. Biol. Fert. Soils. 28, 377- 381.

Gordon, S.A., Weber, R.P. 1951. Colorimetric estimation of indole acetic acid. Plant Physiol. 26, 192- 195.

Kang, B.R., Yang, K.Y., Cho, B.H., Han, T.H., Kim, I.S., Lee, M.C., Anderson, A.J., Kim, Y.C. 2006. Production of indole-3- acetic acid in the plantbeneficial strain Pseudomonas chlororaphis O6 is negatively regulated by the Global Sensor Kinase GacS. Curr. Microbiol. 52,473- 476.

Karnwal, A. 2009. Production of indole acetic acid by fluorescent Pseudomonas in the presence of Ltryptophan and rice root exudates. J. Plant Pathol. 91,1, 61- 63 . 
Koo, So-Yeon, Kyung-Suk Cho. 2009. Isolation and Characterization of a Plant Growth-Promoting Rhizobacterium, Serratia sp. SY5. J. Microbiol. Biotechn. 19,11, 1431- 1438.

Leveau, J.H.J., Lindow, S.E. 2005. Utilization of the plant hormone indole-3-acetic acid for growth by Pseudomonas putida strain 1290. Appl. Environ. Microbiol. 71, 2365- 2371.

Lugtenberg, B., Kamilova, F. 2009. Plant growth promoting rhizobacteria. Ann Rev Microbiol. 63, 541-556.

Matsukawa, E., Nakagawa, Y., Limura, Y., Hayakawa M. 2007. Stimulatory effect of indole-3-acetic acid on aerial mycelium formation and antibiotic production in Streptomyces spp. J Actinomycetol. 21, 32-39.

Monteiro, A.M., Crozier A., Sanberg, G. 1988. The biosynthesis and conjugation of indole-3- acetic acid in germinating seeds and seedlings of Dalbergia dolichopetala. Planta. 174, 561- 568.

Persello-Catieaux, F., Nussaume, L., Robaglia, C. 2003. Tales from the underground: molecular plant-rhizobacteria interactions. Plant Cell Environ. 26,189-199.

Phi, Q.T., Oh, S.H., Park, Y.M., Park, S.H., Ryu, C.M., Ghim, S.Y. 2008. Isolation and character- ization of transposon-insertional mutants from Paenibacillus polymyxa E681 altering the biosynthesis of indole-3-acetic acid. Curr. Microbiol. 56, 5, 524- 530 .

Plackett, R.L., Burmann, J.P. 1946. The Design of optimum multifactorial experiments. Biometrica. 33, 305-325.

Spaepen, S., Vanderleyden, J., Remans, R. 2007. Indole-3-acetic acid in microbial and Microorganism-plant signaling. FEMS Microbiol. Rev. 31, 4, 425- 448.

Suzuki, Sh., He, Y., Oyaizu, H. 2003. Indole-3-acetic acid production in Pseudomonas fluorescens HP72 and its association with suppression of creeping bentgrass brown Patch. Curr. Microbiol. 47, 138- 143 .

Takai, K. Hayaishi, O. 1987. Purification and properties of tryptopahm side chain oxidase types I and II from Pseudomonas. Methods Enzymol. 142, 195- 217.

Teale, W.D., Paponov, I.A., Palme, K. 2006. Auxin in action: signaling, transport and the control of plant growth and development. Mol. Cell Biol. 7, 847- 859 . 
